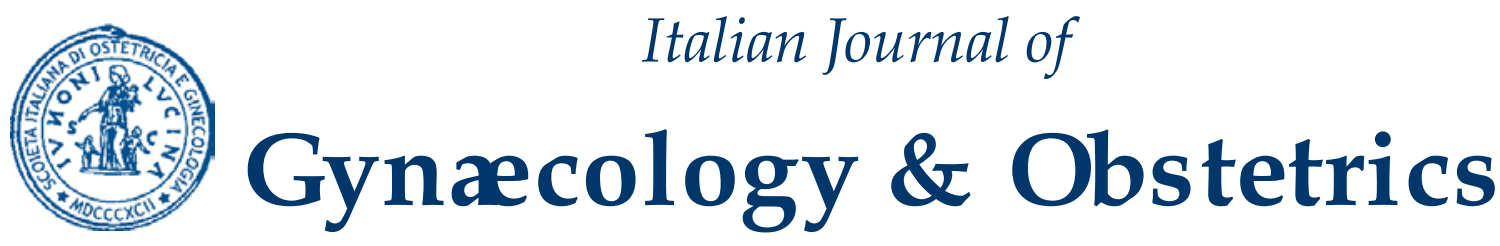

March 2020 - Vol. 32 - N. 1 - Quarterly - ISSN 2385 - 0868

\title{
Recurrence of aggressive angiomyxoma of the vulva: a case report
}

\author{
M. Ferrara1 ${ }^{1}$ G. Scibilia², B. Pecorino², P. Scollo ${ }^{2}$
}

${ }^{1}$ Department of General Surgery and Medical Surgical Specialties, Gynecological Clinic of the Policlinico Universitario

2Department of Obstetric-Gynecology, Cannizzaro Hospital, Catania, Italy

\section{ABSTRACT}

Aggressive angiomyxoma (AA) of the vulva is a rare mesenchymal neoplasm that typically affects women of childbearing age, with a high rate of local recurrence. We present the case of a 38-year-old woman with local recurrence of aggressive angiomyxoma of the vulva 5 years after surgical excision of the first lesion. Aggressive angiomyxoma is diagnosed by histopathological and immunohistochemical features. The therapy is surgical, followed by a long follow-up or hormonal therapy to prevent recurrence.

\section{SOMMARIO}

L'angiomixoma aggressivo (AA) della vulva è una rara neoplasia mesenchimale che colpisce tipicamente le donne in età fertile, con un elevato tasso di recidiva locale. Presentiamo il caso di una donna di 38 anni con recidiva locale di angiomixoma aggressivo della vulva dopo 5 anni dall'escissione chirurgica della prima lesione. L'angiomixoma aggressivo si diagnostica mediante le caratteristiche istopatologiche e immunoistochimiche. La terapia è chirurgica, seguita da un lungo follow-up o terapia ormonale per prevenire la recidiva.
Corresponding Author: Martina Ferrara

martiferra@hotmail.it

Copyright 2020

DOI: $10.36129 /$ jog.32.01.04
Key words: Angiomyxoma; vulvar neoplasms; mesenchimal tumor; case report; local recurrence 


\section{INTRODUCTION}

Aggressive angiomyxoma (AA) is a rare onset mesenchymal neoplasm that affects the pelvic and perineal region in reproductive age. It most frequently affects women in the fourth decade of life. It is a benign neoplasm first described in 1983 by Steeper and Rosai (1). It is characterized by a slow increase in volume, a high rate of local recurrence and a low tendency to metastasize (2).

\section{CASE PRESENTATION}

A 38-year-old woman, G1 P1 (one cesarean section), comes to our observation following the onset of vulvar neoformation on the large left lip of about $5 \mathrm{~cm}$ in diameter. The lesion appears of a soft consistency, movable on the superficial and deep planes and covered by apparently healthy skin. The patient reports, in her anamnesis, about 5 years ago, excision of cysts of the left Bartolini's gland with histological outcome of "aggressive deep angiomyxoma". Performs MRI of the pelvic excavation which highlights "at the level of the large left lip, presence of an elongated aspect extending in an antero-posterior direction for about $6 \mathrm{~cm}$, with maximum thickness at anterior level of $14 \mathrm{~mm}$ with significant contrast enhancement after administration of contrast agent. The patient, with suspected recurrence of aggressive angiomyxoma of the vulva, is therefore subjected to surgical exeresis of the vulvar neorfomation (figures 1-3). The histological examination confirms the diagnosis of aggressive deep angiomyxoma, with immuno-histochemistry of desmin positive neoplastic cells, smooth muscle actin (SMA), estrogen receptors, progesterone, CD34. The margins of resection are undamaged. It is therefore included in a sixyear follow-up program for 5 years.

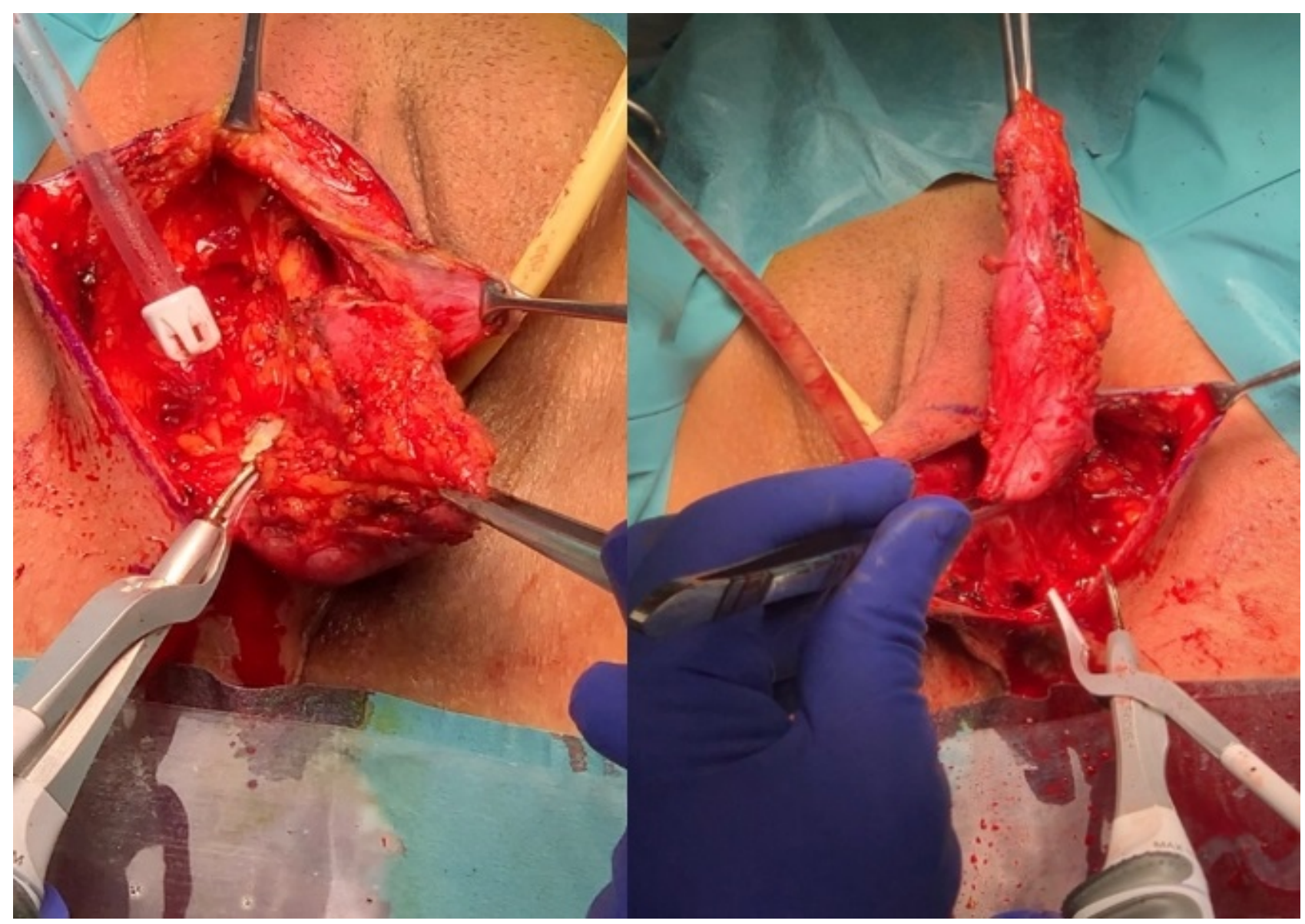

Figure 1-2. Surgical excision of the vulvar AA. 


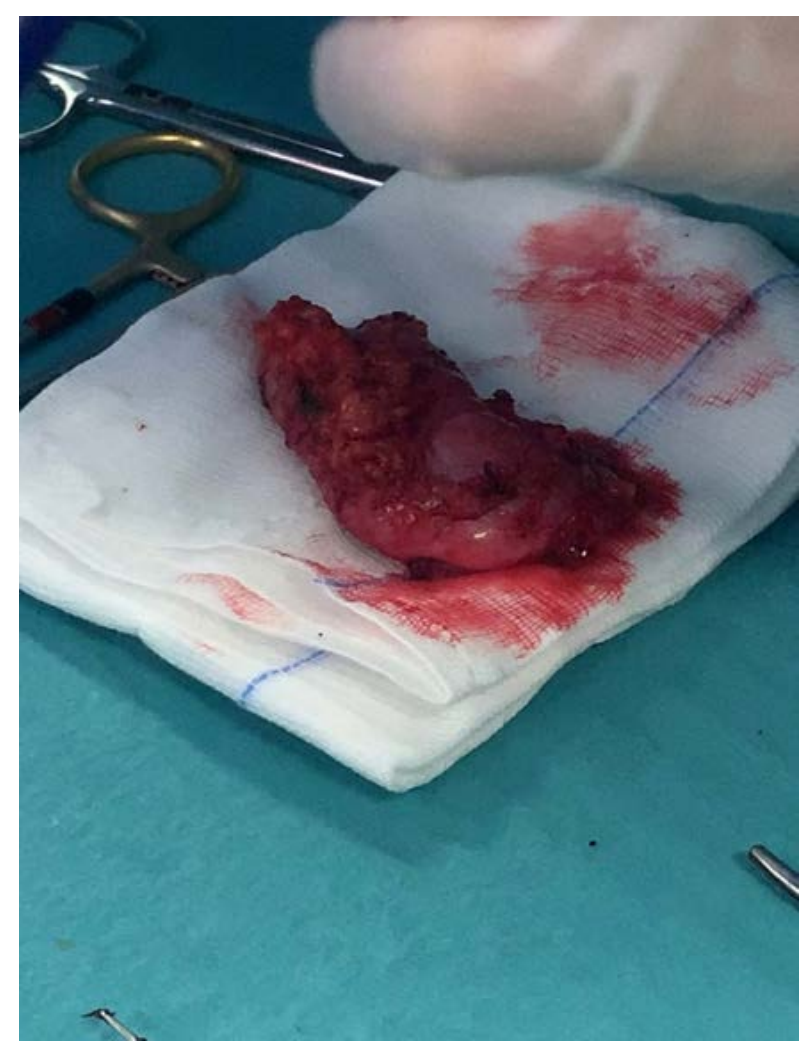

Figure 3. AA after surgical excision.

\section{DISCUSSION}

Aggressive angiomyxoma is a benign mesenchymal tumor that affects almost exclusively the genital, perineal and especially the vulva of women of reproductive age. It is characterized by slow growth but a high rate of recurrence even after several years after the first diagnosis (3). AA is mistakenly diagnosed in $80 \%$ of cases. Clinically it is, in fact, initially recognized as a cyst of the Bartolini's gland, lipoma, cyst of the small or big vulvar lip, Gartner duct cyst, etc. It enters in differential diagnosis also with neoformations such as superficial angiomyxoma, angiomyofibroblastoma, cellular angiofibroma, leiomyofibroma and any polypoid neoformation of the perineum. In fact, it appears as a soft neoformation, such as to make the real evaluation of its volume difficult because of its consistency and its tendency to deeply invade the pelvic tissues, covered by healthy skin. It can be symptomatic and present with vulvodynia, dysuria, sense of weight or occasionally found during a gynecological check-up (4). Therefore the clinical diagnosis is very complex due to the rarity of this formation and the symptomatology common to other lesions of the genital sphere which sometimes appears shaded or completely absent. For this reason it is possible to use different diagnostic methods for images that include ultrasound, Computed Tomography and Magnetic Resonance. Among these, Magnetic Resonance (MRI) plays a greater role due to the greater amount of information it provides (5). Indeed, MRI shows the isointense lesion in T1weighted and hyperintense images in T2weighted images due to the high-water content and the presence of free AA-typical mixoid matrix. It also allows a precise evaluation of the overall volume of the new formation and its limits with respect to the surrounding structures (6). The diagnosis is given by a set of histopathological features such as: stellate and spindle cells with poorly defined cytoplasmic margins and separated by abundant myxoid stroma and fibrillar collagen. The AA is also characterized by a well-represented vascular component with many thin vessels. There is no evidence of atypical mitotic activity or cellular atypia (7). Immunoystrochemistry of the lesion is characterized by receptors positive for estrogens, progesterone, vimentin, desmin, SMA, CD34 and CD44 and always negative for S-100, carcinoembryonic antigen (CEA) and keratin. There is no consensus regarding the pathogenesis of this lesion. Recent cytogenetic studies have shown the presence of genetic alterations affecting chromosome 12 , in the $12 q 13-15$ region. In this region there is the HMHI-C gene (high mobility group protein isoform C) that encodes proteins involved in the regulation of gene transcription involved in the pathogenesis of AA. The possibility of using mutated anti-HMHI-C antibodies could be used to identify microscopic residue of neoplasia (8).

\section{CONCLUSIONS}

Therapy in the first instance is therefore excisional surgery, followed by follow-up or hormonal therapy. The hormonal treatment based on tamoxifen, raloxifene or Gn-RH analogues finds space in case of partially excised bulky lesions or in the treatment of relapses. Chemotherapy and radiotherapy are not useful in the treatment of these lesions due to the poor mitotic activity of the AA (9). Finally, it is im 
portant to keep in mind that AA is characterized by a high rate of recurrence that can occur even after many years, so it is important to set a follow-up period of not less than 5 years.

\section{CONFLICT OF INTERESTS}

The authors declare that they have no conflict of interests. 


\section{REFERENCES:}

(1) Steeper TA, Rosai J. "Aggressive angi-omyxoma of the female pelvis and perineum. Report of nine cases of a distinctive type of gynecologic soft-tissue neoplasm," American Journal of Surgical Pathology, vol. 7, no. 5, pp. 463-475, 1983. (2) Lee KA, Seo JW, Yoon NR, Lee JW, Kim BG, Bae DS. Aggressive angiomyxoma of the vulva: A case report. Obstet Gynecol Sci 2014;57:164-7. (3) Geng J, Cao B, and Wang L. "Aggressive angiomyxoma: an unusual presentation" Ko-rean Journal of Radiology, vol. 13, no. 1 pp. 90-93, 2012.

(4) Sutton BJ, Laudadio J. 2012 "Aggressive angiomyxoma” Arch. Pathol. Lab. Med. 136 (2), 217-221 Feb.

(5) Chen H, Zhao H, Xie Y, Jin M. 2017 May. Clinicopathological features and different diagnosis of aggressive angiomyxoma of the female pelvis: 5 case reports and literature review. Medicine (Baltimore) 96 (20), e6820.
(6) Srinivasan S, Krishnan V, Ali SZ, Chidam-baranathan N. "Swirl sign' of aggressive angiomyxoma- a lesser know diagnostic sign", Clinical Imaging, vol. 38, no. 5, pp. 751-754, 2014. (7) Van Roggen JFG, Van Unnik JAM, Briaire-De Bruijn IH, Hogendoorn PCW. "Aggressive angiomyxoma: a clinicopathological and im-munohistochemical study of 11 cases with long-term follow-up," Virchows Archiv, vol. 446, no. 2, pp. 157-163, 2005.

(8) Nucci MR, Fletcher CD. "Vulvovaginal soft tissue tumors: Update and review". His-topathology 2000; 36:97-108.

(9) McCluggage WG, Jamieson T, Dobbs SP, Grey A. "Aggressive angiomyxoma of the vulva: dramatic respons to gonadotropin-releasing hormone agonist therapy". Gynecol Oncol 2006; 100:623-5. 